\title{
Ein unbestechlicher Pharmakritiker
}

Anna Sax

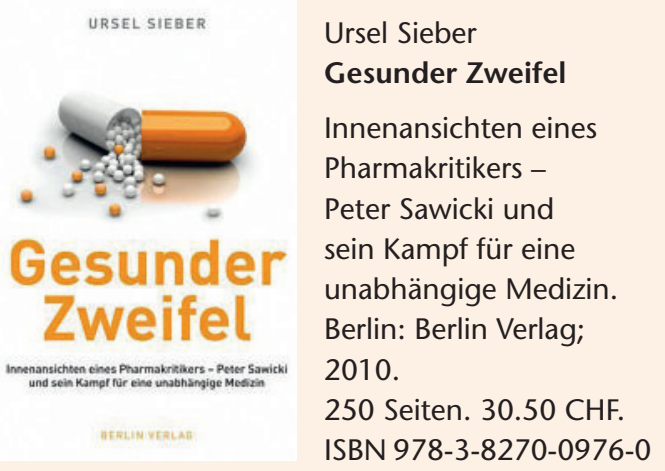

Das 2004 in Deutschland gegründete Institut für Qualität und Wirtschaftlichkeit im Gesundheitswesen (IQWiG) war vielen wirtschaftsnahen Politikern und Lobbyisten von Anfang an suspekt. Verstärkt wurde das Misstrauen durch die Wahl eines Institutsleiters, der für seine Fachkompetenz ebenso bekannt war wie für seine undiplomatischen Auftritte: Peter Sawicki, der einen lukrativen Chefarztposten verlassen hatte, um der evidenzbasierten Medizin in Deutschland zum Durchbruch zu verhelfen, passte nicht in die Maschinerie des Gesundheitswesens. Nach dem Regierungswechsel war Sawicki endgültig zum Abschuss freigegeben: Wegen einer sogenannten Dienstwagen-Affäre musste er Ende August 2010 seinen Platz räumen. «Ich war ein Systemunfall», erklärte er später der Autorin des Buches über seinen Aufstieg und Fall als Leiter des IQWiG.

\section{Interessant ist die Schilderung des Widerstands, der einer unabhängigen und evidenzbasierten Medizin von der Pharmaindustrie - und überraschenderweise auch von den Krankenkassen - entgegenschlägt.}

Korrespondenz: Lic. oec. publ. Anna Sax Postfach 2160 CH-8026 Zürich sax@oekonomin.ch
Die Medizinjournalistin Ursel Sieber hat den Weg des unbequemen Zeitgenossen und unbestechlichen Pharmakritikers zurückverfolgt. Sie sprach mit seinen Weggefährten und Gegnern und zeichnet ein differenziertes Bild der Person von Peter Sawicki. Wichtiger als dieses Porträt ist jedoch die Schilderung des Widerstands, der einer unabhängigen und evidenzbasierten Medizin seitens der Pharmaindustrie - und überraschenderweise auch seitens der Krankenkassen - entgegenschlägt.
Den Nutzen von über 50 Medikamenten gegen die grossen Volkskrankheiten sollte das IQWiG überprüfen, darunter Blockbuster wie das Kunstinsulin Lantus von Sanofi Aventis. Anhand mehrerer Beispiele zeigt Sieber in ihrem Buch auf, wie die Industrie über Jahre hinweg Informationen zurückhielt, die es dem IQWiG ermöglichen sollten, seine Aufgabe zu erfüllen. Zudem wurde es zunehmend schwieriger, unabhängige Wissenschaftler zu finden, die bereit waren, für das IQWiG zu forschen. Denn wer mit Sawickis Institut zusammenarbeitete, musste befürchten, künftig keine Fördergelder mehr von der Pharmaindustrie zu erhalten. Doch damit nicht genug: Sawicki, der beharrlich nach randomisierten, kontrollierten Studien verlangte, sah sich zunehmend verleumderischen Angriffen auf seine wissenschaftliche und persönliche Integrität ausgesetzt.

Sawicki selbst nimmt allerdings auch kein Blatt vor den Mund, wenn es darum geht, die Kritiken an seiner Arbeit und an seiner Person zu kontern. Er sei kein Feind der Pharmaindustrie, verteidigt er sich gegen das Etikett des Pharmagegners: «Wer soll denn Medikamente herstellen? Aber wir brauchen eine Industrie, der wir vertrauen können, die uns nicht betrügt, die keine Studien unterschlägt, die keine Leute besticht.»

Was dieses Buch lesenswert macht, sind einerseits die sorgfältig recherchierten Fallbeispiele, andererseits aber auch die Hinweise auf Systemfehler im Gesundheitswesen, wie etwa die «Mehrkostenverträge», wie sie die Krankenversicherer mit einzelnen Pharmafirmen abschliessen, um auch Medikamente vergüten zu können, die bei der Nutzenbewertung durchgefallen sind. Aktuell im Hinblick auf die Einführung der DRG in der Schweiz ist der «Verbotsvorbehalt», der es Spitälern erlaubt, neue Therapieverfahren einzuführen, die noch nicht in Studien überprüft worden sind. Bezahlt werden diese neuen Verfahren in Deutschland über eine Sondervergütung für «neue Untersuchungs- und Behandlungsmethoden» (NUB). Was für die Spitäler und die Industrie (auch in der Schweiz) «innovationsfreundlich» ist, bezeichnet Sawicki als «unkontrolliertes Experiment».

Nicht zuletzt beinhaltet Siebers Buch einen konkreten Vorschlag, wie die Abhängigkeit der medizinischen Forschung von der Pharmaindustrie gelockert werden könnte: Aus einem Fonds, gebildet von den Krankenkassen und der Industrie, sollen unabhängige Studien finanziert werden. Diese Forderung erhebt inzwischen auch der Vorsitzende der Arzneimittelkommission der deutschen Ärzteschaft. Vielleicht hat er mehr Glück damit als Peter Sawicki. 